\title{
As experiências da arte como necessidades da vida
}

\section{Editorial}

A edição n. o 10 da Revista Visuais apresenta artigos de pesquisadores de diferentes instituições do Brasil, de Portugal e da Espanha. Vale destacar que a Revista Visuais tem em perspectiva abrir espaço para textos que se relacionem com a teoria e a crítica da arte, com a experiência da arte, e em particular com os textos produzidos por artistas e pesquisadores relacionados às complexidades do processo criativo na arte. Assim, esperamos contribuir e dar continuidade na missão da Revista Visuais que é abrir seu espaço para a publicação das investigações em artes visuais, nas suas várias possibilidades e articulações.

Existem objetos e imagens que habitam a duração do tempo, onde sobrevivem às ruinas de suas camadas de nascimento, quando permanecem no tempo da história. Nessa condição, num outro desígnio de oportunidades, o esquecimento não apaga o feito, nem ele é soprado pela insignificância de ter acontecido, mas depende de uma atribuição de interesse, do foco de oportunidade, para comunicar sua existência ao outro. Diante da arte, o tempo dos objetos se estabelece em camadas, e seus espaços estão demarcados pelo processo inventivo que uma pesquisa possa oferecer ao conhecimento. Nesses objetos, materialidades e subjetividades foram carregadas pela criação e certas chaves de oportunidade são necessárias para acessar o tempo e as singularidades dessas experiências.

Não está em causa, numa pesquisa em artes visuais, apenas aquilo que se pode guardar nos museus, mas também aquilo que o esquecimento poderia apagar. Se trabalharmos a partir dos repertórios imaginários, estes nos servem para encontrar alguma coisa além de uma simplória discussão sobre a utilidade dos objetos na resistência da vida, assim, teremos que reconhecer a diversidade das culturas e das experiências, por isso cada fragmento que encontramos pode nos servir para anexar uma consciência de mundo.

Pensamos na formatividade e nas histórias marcadas nestes objetos e nos processos da arte, cujos sentidos, em complexidade, se determinam nas experiências e nas nescessidades antecedentes ao próprio gesto de acontecimento. A pesquisa poderá nos conduzir num passo aquém dos escombros, ou de fatos que a história ainda não adicionou, ou alguma relação que podemos avaliar em contra-campo. 
Nessa condição de abertura da pesquisa em artes e de sua comunicação pública, partimos na direção daqueles corpos consentidos pela fatura dos artistas que fundem suas marcas expressivas nas matérias ou determinam uma recusa de expressão em favor de um objetivo conceitual e que as experiências da arte surgem como necessidades da vida, numa abertura que desconhece o epílogo, mas se constitui a partir de singularidades conexas.

Isabel Sabino da Faculdade de Belas-Artes de Lisboa, nos apresenta Tears in rain (ou "Lido com ela", de novo), texto em que faz uma consideração sobre uma exposição realizada "a partir de um convite para expor numa cidade na periferia de Lisboa", um projeto artístico "construído num local determinado: um cinema em ruínas chamado Lido". Seu texto "é sobre esse projeto em mediação com o local (...) sobre a coexistência, em pintura contemporânea, de uma dupla dinâmica entre a energia vital e a pulsão melancólica".

Fernando Cury de Tacca, professor do Instituto de Artes da UNICAMP, em seu artigo Camilo José Cela e a fotografia analisa as suas obras no intercruzamento entre fotografia e literatura, nos apresenta um escritor espanhol de fundamental importância para a cultura ibérica, tendo recebido, entre outras laureas, o Prêmio Nobel de Literatura em 1989. Camilo José Cela teve "uma relação com a fotografia muito profícua desde o final dos anos 40. Com muitos livros paradigmáticos publicados entre os quais muitos propiciam uma atmosfera de realidade imagética, entretanto, construída pela ficção, sendo assim um pioneiro na exploração de uma relação complementar entre imagem-texto em seu processo criativo".

Ricard Huerta da Universidade de Valência, nos apresenta Visibilidade LGBT em tempos de "gilets jaunes" analisando espaços culturais alternativos em Paris onde nos apresenta "uma abordagem para diferentes espaços culturais alternativos franceses a partir de uma perspectiva LGTB". Sua investigação parte de uma experiência pessoal realizada em Paris durante 2018 e 2019.

Susana Piteira, da Faculdade de Belas Artes da Universidade do Porto / I2ADS, em Entre a floresta e o jardim. Alberto Carneiro e o tamanho da terra apresenta a obra de Alberto Carneiro, um artista português que "a partir de uma nova atitude perante a natureza" nos apresenta informações "sobre componentes intrínsecas da prática da arte e da escultura, através do território", ou seja, de suas relações com seus espaços ampliados.

Renan Marcondes, performer e doutorando do PPG Artes da Cena da USP em "Lembrar. Lembrar de novo. Lembrar melhor. Arte da performance e história sem progresso" se propõe a discutir relações "entre arte da performance e suas lógicas de arquivo". Para isso procurou estabelecer "um breve panorama dos principais debates internacionais realizados a partir dos anos 1990" nesta área. Ele incluiu em seu texto um trabalho artístico, de sua autoria, para situar em si mesmo um encontro, relacionando a "noção de tragédia" como "um vetor para pensar sobre a documentação de arte da performance". 
Camila Damico Medina da Universidade Federal do Rio de Janeiro no texto Disruptiva: Memória sobre o comportamento do público em exposições de arte e tecnologia se propõe a "questionar metodologicamente a delimitação de uma negação do espaço dos afetos para pesquisa sobre as disputas do lugar do espectador em modelos expositivos mais laboratoriais". A pesquisadora se propõe à "observação participante na situação de visitação", assim seu texto propõe um espaço de aproximação entre os atores e interatores "numa exposição de arte e tecnologia".

Mariana Vasconcellos, historiadora e discente do PPG Artes Visuais da UFRGS nos apresenta o texto As "formas simbólicas" na pintura tardia de Gustave Moreau. Especulações sobre uma abordagem da arte, onde considera "analisar o papel exercido pelos elementos pictóricos de desenho e colorido dentro da pintura tardia do artista oitocentista francês Gustave Moreau". Para seu estudo Mariana se aproxima do conceito de "forma simbólica" a partir das "concepções de Ernst Cassirer e Erwin Panofsky".

\section{Mauricius Martins Farina}

Editor da Revista Visuais 